\title{
Rebalancing the Poles in Mark C. Taylor's (A)Theology
}

\section{David Henry Nikkel}

University of North Carolina, Pembroke

\begin{abstract}
Mark C. Taylor's After God offers resources for constructive theology, or (a)theology, as it develops an ontology of complexity. Taylor posits two poles pertaining to self-organizing wholes: (I) that of the formation of structures and (2) that of destabilizing or disrupting structures. While Taylor prioritizes the destabilizing pole, this article argues that this preference is misguided and offers a corrective intended to yield a more viable theology of complexity. It makes its case in terms of both theology/metaphysics and natural science. It concludes that when it comes to God or the divine, an equal valorization of the structuring and destabilizing poles commends itself, while in the case of finite creation, our experience of reality supports a priority to the structuring pole. Attendant to this second conclusion, Taylor's position results in too close an entailment of the human with the divine. Finally, this article argues that Taylor's emphasis on the destructuring pole discourages the most effective means to confront our contemporary situation "far from equilibrium," a situation so well depicted by Taylor, namely, through reforming Christianity and other world religious traditions.
\end{abstract}

\section{Keywords}

chaos, complexity, destabilizing pole, dipolarity, dualism, God or the divine, monism, possibility, self-organization, Mark C. Taylor

\section{Introduction}

In his recent work focusing on complexity, After God, ${ }^{1}$ Mark C. Taylor has greatly enriched our resources for doing constructive work in (a)theology. Indeed, for those who regard themselves both as academic theoreticians of religion and as

1. Mark C. Taylor, After God (Chicago: University of Chicago). References hereafter will appear as page numbers in parentheses in the text of this article.

\section{Corresponding author:}

David Henry Nikkel, University of North Carolina, P.O. Box 15I0, Pembroke, NC 28372-15I0.

Email: david.nikkel@uncp.edu 
theologians, particularly in the Western theological tradition, there is even more to like about Taylor's project. Drawing on that tradition, he insists that we cannot finally separate religious theory and practice, academic scholarship and theology. As he asks rhetorically, "Is theory ever non-theological?" A resounding "No" is the obvious answer for Taylor. ${ }^{2}$ In the process he has acknowledged the limitations of deconstructionist approaches with their unrelenting negativity, while developing an ontology (dare one even say a metaphysics?) that posits two poles: (1) a pole pertaining to the making of meaningful forms and structures and (2) a destabilizing pole of deformation and disruption of meaning.

Taylor has declared his preference for one of these poles, that of destabilization. Moreover, one can find instances in his work where he clearly associates the destructuring pole, but not the pole of structure-making, with the divine. While there is much in Taylor's theology that Christian and other theologians can accept, I claim in this article that Taylor's prioritization of disruption is misguided on several fronts. Correcting for that over-emphasis results in a more viable theology of complexity. The article will make this case in terms of theology/metaphysics and of science. Given that theories of complex systems have their original home in the natural sciences, it is apropos that I invoke elements of physics and then biology (as does Taylor). Contrary to Taylor, I will conclude that when it comes to God or the divine, an equal valorization of the structuring and destabilizing poles commends itself, while in the case of finite creation, of our universe and us human beings, our experience of reality supports a priority to the structuring pole. Attendant to this second conclusion, Taylor's position results in too close an entailment of the finite and the human with the undifferentiated/undifferentiating divine. Finally, I will argue that Taylor's accentuating the destructuring pole discourages the most effective way to confront our contemporary cultural, social, political, economic, environmental, and religious situation "far from equilibrium" depicted so well by Taylor.

As suggested at the start of this article, Taylor offers a model of "complexity" as the best way to understand reality, the divine, and their interrelationship. Indeed, Taylor advocates complexity as a tertium quid with respect to the opposing, wrongheaded options of monism and dualism. Under monism as interpreted by Taylor, identity and the making of form completely subsume or abrogate difference and the destabilization of form. With respect to dualism for Taylor, we can say that identity and the making of form are associated with the divine and positive reality, while difference and destabilization are associated with evil reality. Taylor writes that complexity involves "identity-in-difference" and "difference-in-identity," "spontaneous self-organization," and "emergent creativity." On one level it would seem that, when it comes to the "relation of identity and difference," Taylor should opt for a "both-and" relationship, in that identity and difference "are not oppositional" but "codependent," as actual entities interconnect in complex

2. Mark C. Taylor, "Refiguring Religion," Journal of the American Academy of Religion 77 (2009): $105 f f ., 117$. 
ways $(38,40)$. Taylor though reserves the "both-and" moniker for monism, presumably because everything ultimately is one and the same reality. Instead he officially characterizes his model of complexity as one of "neither-nor." Relative to identity and difference, we have neither simple identity nor absolute difference.

Self-organization serves as an ultimate principle for Taylor. Yet for Taylor selforganized wholes do not constitute the "locus of the real" or divine. Such a locating of the real in self-organized wholes would allow for a both-and with respect to transcendence/immanence and absence/presence à la panentheism, as each entity includes various parts, but only the divine as most fully real includes everything actualized up to this point in time. Moreover, it would provide for a both-and relationship in terms of identity and difference. Self-organized wholes have an integrity distinguishing them from other wholes, while at the same time connections and similarities pertain among those wholes; indeed, most wholes form part of larger wholes. Additionally, parts of wholes contribute to, without being identical with, the whole that is more than the parts or their sum, while wholes influence their parts. This model of self-organizing wholes as entailing both-and with respect to identity and difference would also cohere with a panentheistic concept of the divine: the world constitutes a crucial part of the identity of the God or divine who also transcends it. Interestingly, Taylor's understanding of the relationship between part and whole seems congruent with the both-and scheme delineated just above: "Whole and parts [are] reciprocally related: whole emerges from but cannot be reduced to parts" (330). Furthermore, "self and other, part and whole, local and global are mutually constitutive and, therefore, must emerge and develop together" (356). Thus I suggest that a "both-and" relationship best fits with complexity, rather than Taylor's yoking of "neither-nor" with complexity.

\section{Taylor's Preference for the Destabilizing Pole}

Instead of self-organized wholes as locus of the real, Taylor identifies "the virtual" as "the elusive real in and through which everything that exists comes into being and passes away" (40-41). As the elusive reality that allows for self-organized wholes, it is neither transcendent nor immanent, neither absent nor present, according to Taylor $(38,41)$. In his words, the virtual is

Always betwixt and between, it is neither immanent nor transcendent-neither here and now nor elsewhere and beyond. To the contrary, the virtual is something like an immanent transcendence, which is inside as an outside that cannot be incorporated. This interior exterior or exterior interior is the source of the endless disruption that keeps complex systems open and makes them subject to constant transformation yet also preserves them from disintegration and simple extinction. Nothing remains stable, secure, or certain; rather than forces to be repressed, instability, insecurity, and uncertainty are the conditions of creativity. Disorder is not the opposite of order but, if it does not lead to systematic collapse, can make new forms of order possible. (41) 
As stated in the opening paragraph, Taylor does posit a both-and dipolarity within complex systems of a structuring/stabilizing element and a deconstructing/ destabilizing element. However, his valorization of the virtual manifests his favoritism for the latter element. In an interview with the Columbia News, Taylor declared his preference for the disfiguring pole. ${ }^{3}$ Indeed, it appears to be tantamount to this elusive virtual. Taylor associates the de-structuring, undifferentiating element with the experience of the sublime, which he further associates with the experience of unlimited possibility (119-24). Taylor favorably invokes Kant and continues,

\footnotetext{
"The sublime is to be found in an object even devoid of form, so far as it immediately involves, or else by its presence provokes a representation of unlimitedness, yet with a super-added thought of its totality." The beautiful, then, is associated with form, limit, and figure, and the sublime with formlessness, the unlimited, and the unfigurable. (123)
}

Furthermore, Taylor characterizes unlimited possibility as origin and ground: "Far from blocking representation and self-representation, the unrepresentable is the origin of its infinite excess. Infinite obscurity is what makes endless creativity possible" (120). The "unnamable bears many names: origin of that which has no origin, groundless ground, abyss, freedom, imagination, creativity" (121). Speaking of imagination, Taylor declares that "The figures that the productive imagination forms are arbitrary insofar as they are not determined by other figures but are freely formed and thus original" (115, emphasis Taylor's). Indeed, "Just as God creates freely ex nihilo [in traditional Christian theology], so the productive imagination creates freely out of nothing" (116). Thus, we can clearly see the high value, indeed ultimate value, that Taylor places on the destabilizing element associated with possibility, freedom, creativity, and imagination - and that humans participate in that which is ultimately real.

\section{Theological/Metaphysical Considerations}

Given Taylor's valorization of the element of deformation, it will advance our purposes to look at how Taylor views this element in terms of ultimate causes or origins, both metaphysically and relative to the physical universe. To reference the story, of uncertain origin, about a dialogue between a scholar and a woman who claimed the earth rested on the shell of a giant turtle and who, when challenged as to what that turtle stood upon, responded, "It's turtles all the way down," for Taylor it is the element of abysmal, indeterminate, and disruptive possibility "all the way down."

In a key passage, Taylor does a metaphysical assessment of the "Logos" dimension of reality. There he recognizes "something like mind or Logos at work within

3. "Q \& A with Religion Professor Mark C. Taylor," Columbia News (January 3, 2008). 
this process" of self-organizing wholes (346). One possible position would entail that "Logos" refers to structures in accordance with which all self-organizing realities in the universe emerge. This could allow for indeterminacy but would maintain that the various outcomes subject to determination fall within ranges set by these structures. Under this model the structures themselves need not change. Taylor, though, holds a contrary opinion:

This mind or Logos emerges through the self-organization of the autopoietic process of life. Never fixed or stable, this is a nonlogocentric Logos that is figured, disfigured, and refigured through the dynamic morphogenesis of the constitutive networks from which it emerges and, in turn, shapes. (346)

Regarding ultimate origins and causes, one could hold that it is "self-organization all the way down" in a manner that gives equal priority to the structured and unstructured poles in relation to a cause behind the universe and perhaps within the universe. However, for Taylor an obvious asymmetry rules. As just above, Logos emerges from the abyss of possibility, not the other way around, nor is there mutual emergence. Or as Taylor puts it elsewhere, the structures or principles relevant to self-organization themselves arise out of "an-archy" (literally, "no ruler," 164). Expounding upon the abyss, Taylor states that it is "no-thing" but "not nothing," for "it is the anticipatory wake of the unfigurable that disfigures every figure," which "is the condition of the possibility of creative emergence" (345). Logos by way of contrast does not constitute a part of the possibility of creative emergence. And as noted above, imagination creates or in-forms "arbitrarily," not informed by any structure, "creates freely out of nothing." Clearly then, the unlimited, the indeterminate, the disfiguring element claims metaphysical ultimacy in Taylor's system.

\section{Scientific Considerations}

\section{Physics}

Of course, concepts surrounding self-organizing complex systems arose first in the natural sciences, more specifically in physics. So it behooves us to look at Taylor's take on science relative to the poles of structuring and de-structuring. As we would expect, the physical laws of the universe themselves self-organizationally evolve, according to Taylor (322-23). In support he cites physicist Lee Smolin, interpreting Smolin as maintaining that "the laws of physics and the structure of the cosmos... are not fixed and eternal but evolve according to the principle of natural selection" (323). Thus, for Taylor the laws and structures of the universe change through time and vary among different regions of the universe. If that reading were correct, Smolin's position would overthrow the consensus of physicists. As I will claim shortly, it is not. 
The consensus in physics holds the following: at the time of the Big Bang, the fundamental forces and basic laws of the universe may well have been up for grabs. (Note that this does not mean that the possibilities were unlimited; they may well have lain within certain ranges.) However, within the first split second of the Big Bang, these indeterminacies of the forces and regularities of nature were determined in a process of differentiation and have remained stable for the past 13.7 billion years. This applies to the four basic forces, laws of motion, relativity, quantum mechanics, how subatomic particles form, how elements change relative to the number of protons in the nucleus, and how complex systems develop in situations far from equilibrium. I would stress that much of our knowledge about the universe, including its age and the evolution of the various types and generations of stars and galaxies, depends upon the uniformity of these laws or structures throughout the temporal and spatial expanse of the universe.

Does Smolin believe in the mutability and localization of the laws of our universe? I believe Taylor misreads Smolin's The Life of the Cosmos. Smolin holds to a particular multiverse theory, in which each black hole spawns a new universe. It is in the inflationary beginnings of each new universe that natural selection applies, as particular values that allow for a highly structured universe are chosen from among the relevant parameters in the case of universes that sustain life. As in the consensus of physicists, much happened in the first fractions of a second of inflation of our universe. ${ }^{4}$ Smolin does refer to a boundary to our knowledge about the universe's past, when it was opaque to light, which lasted for about one million years after the start of the Big Bang. With our present technology, we cannot go back any further to measure what happened, and Smolin allows that some facets of the universe's structures and laws may have been up for grabs during that period. ${ }^{5}$ Smolin also cites the opposite boundary, that pertaining to the future: "It is then always possible that the parameters of the laws of physics are different in some far away region that we will not see until some time in the future. But this seems unlikely." "Smolin in fact avows that we have "quite good evidence that the laws of nature everywhere we can see [that is, all of our universe that emits electromagnetic radiation that reaches us] are the same as on earth." 7 Therefore, after the selection of the structure or laws for a given universe, Smolin does not claim that they change or apply differently to diverse sections of that universe. One possible source of confusion is that sometimes Smolin uses the term "universe" to apply to all the multiverses, all the universes associated with black holes, rather than to our universe, which supposedly is just one of a multitude. ${ }^{8}$ The above assessment would apply to all the multiverse theories entertained by many physicists, whether the super-inflationary

\footnotetext{
4. Lee Smolin, The Life of the Cosmos (New York: Oxford, 1997), 75-106.

5. Smolin, Life of Cosmos, 77-79.

6. Smolin, Life of Cosmos, 78.

7. Ibid.

8. Lee Smolin, "The Unique Universe," Physics World 13 (June 2, 2009).
} 
spawning of new universes allies with quantum mechanics, string theory, black holes, or some combination thereof. Recall that physicists are open to the idea that our universe's laws and structures might have been differently determined at the beginnings of the Big Bang. However, multiverse theory does not provide any reason for thinking that once basic laws have become determinate in the early moments of a new universe that they will change later on.

One could conjecture that localization of physical laws might explain certain mysteries or anomalies in our present scientific knowledge. One candidate might be the accelerating rate of expansion of the universe. Perhaps differing laws in different sections of the universe control the expansion rates? An empirical problem arises for this possible explanation: with respect to the rates of expansion of those portions of the universe further from the center of the Big Bang than we are, the parts of the universe closer to us are expanding more rapidly than the parts of the universe further out. Most physicists find more plausible the prospect of explaining changes to the rates of expansion in the still very mysterious vagaries of dark matter and energy, which like visible matter and energy, probably do not have uniform distribution throughout the cosmos.

I will mention an observation and interpretation of some astronomers published in October, 2011: the nature of electro-magnetism may vary in different parts of the universe given data on absorption that suggests variation in the fine-structure constant. ${ }^{9}$ This was billed as a challenge to the most basic assumptions of physics by the media that carried it. However, mainstream media did not publicize it, given that this finding is a long way from confirmation. I suspect that, like the neutrinos that appeared to travel faster than the speed of light, a less startling explanation will eventually come forth.

\section{Biology}

Taylor proceeds from physics and cosmology to analyze biological systems. I find much to applaud here, especially his inveighing against the tendency of some biologists to regard the genome as a fixed, rigid program, as well as the proclivity of most biologists to credit the external pressure of the environment on random mutations as the only factor driving evolution (323-34). The evidence against the first tendency includes the following: what potentials of the genetic code become expressed or stay unexpressed often depend upon the environment, as well as perhaps upon the organism's activity; and mutations within organisms increase when undergoing increased stress. With regard to the second tendency, Taylor comes to a perceptive conclusion: the neo-Darwinian synthesis constitutes one side of the dualism endemic to Western thought, namely, the objectivist, externalistic, reductionist side (329-35). He rightly credits the organism with

9. J.K. Webb et al., "Indications of a Spatial Variation of the Fine Structure Constant," Physical Review Letters 107 (October 31, 2011). 
self-organizing power of its own that correlatively puts pressure on the environment. ${ }^{10}$ Taylor does recognize the cruciality of structure in evolution and here the tone is different from his metaphysical rhapsodizing about unlimitedness and arbitrariness:

Evolution is not simply an arbitrary process in which all things are possible. Once development starts down a certain path, alternatives are necessarily limited. Selection and self-organization are complementary: emergent self-organizing structures create networks of constraint within which natural selection can occur. (336)

Nevertheless, Taylor still manifests a preference for the deforming element even in biology and evolution. Framing the two poles in terms of information and noise, an originary priority or ultimacy belongs to the latter: "information is noise in (the process of) formation; there can be neither form nor formation, figure nor figuration, without the noise from which it emerges and to which it returns" (328). On the evolution of species, Taylor emphasizes the upside of noise or mutations:

Just as noise disrupts stable patterns to provide the opportunity for the creative reconfiguration of organizing schemata, so mutations make it possible for organisms to change in ways that enable them to interact more effectively with other organisms as well as the overall environment. Mutations, in other words, are creative disfigurings that allow new figures to emerge. (336)

True. However, mutations more often serve as destructive disfigurings. Even in terms of the individual organism, Taylor emphasizes instability, here quoting Mae-Wan Ho: "genomic DNA is functionally and structurally as flexible and changeable as the rest of the organism" (326).

For a complex biological (or other) system to self-organize within a milieu of lesser complexity, a situation far from equilibrium must occur. On this point, no one can deny the cruciality of Taylor's destabilizing element. Without disequilibrium, life would not have emerged nor would some of its forms have increased in complexity. Yet Taylor does not give sufficient due to the side of maintenance of structure. Once a self-organizing reality has emerged, its basic form normally needs to be maintained for that reality to continue its existence. In the case of an individual biological organism, unless that basic structure is preserved - if the organism finds itself in a situation very far from equilibrium - it suffers a severe consequence, namely death. Of course, the homeostasis of humans and other biological organisms represents a dynamic equilibrium. Yet despite the changes of organisms over the life cycle and at the level of individual cells, a definite complex structure must exist for life to remain. Let me add a word about the stability and instability of

10. Some biologists, demurring from the Neo-Darwinian synthesis, endorse the mutual pressure complex organisms place on the environment. David Nikkel, Radical Embodiment (Eugene, OR: Wipf \& Stock, 2010; Cambridge: James Clark \& Co., 2011), 93-95. 
biological species over time. Negatively, great disequilibrium or instability can result in the extermination of a species in the sense that no descendent species evolve from its tree. Positively, stability has constructive roles to play. Stasis has occurred for many ancient species still thriving today. Moreover, the phenomenon of "punctuated equilibrium" means that periods of overall disequilibrium, where a large proportion of species die or speciate into new ones, are the exception rather than the rule for the span of biological time.

\title{
Taylor's Model of Complexity and the Divine
}

Taylor has moved well beyond his deconstructive phase through his embrace of the importance of holistic meaning-making. He offers this very cogent analysis:

\begin{abstract}
Deconstruction is so preoccupied with the talk of criticism that it cannot provide the constructive gesture so desperately needed to respond to today's raging neofoundationalism. Every system and structure, poststructuralists argue, totalizes by repressing differences and excluding otherness... this strategy ends by committing the opposite error of structuralism: poststructuralism privileges difference to such an extent that any commonality or unity becomes effectively impossible... What poststructuralism cannot imagine is a nontotalizing structure that nonetheless acts as a whole. But this is precisely what complex adaptive networks do. (309-10)
\end{abstract}

Notwithstanding that insight, his preference for the destructuring element probably reflects continuing Derridean deconstructive influence. Notice that his problem with poststructuralism is not privileging difference but the "extent" to which it does so. Continuing poststructuralist influence likely manifests itself in his preference for "neither-nor" relative to presence/absence and transcendence/immanence, as he locates the real or divine and our relationship to it. I will attempt to make the case that Taylor ends up reinscribing a type of dualism over-emphasizing a kind of transcendence, the transcendence of the unrepresentable, unlimited, abysmal, disfiguring element. Deconstruction, while having its immanentist tendencies (insofar as we may be trapped in our representations), also manifests interesting tendencies towards transcendence: différance, the unpresentable, which transcends, which refuses capture by, any form or structure; and the later Derrida's messianic ideal. This messianism - endorsed and expounded upon by John Caputo ${ }^{11}$ _ constitutes a messianism "without content and without [an] identifiable messiah."12 While Derrida grants that this messianic ideal perforce comes from the particularities of tradition(s), it is intentionally a formal concept, a wholly other that challenges in the name of justice the privileged claims of any and all historical social structures or

11. John D. Caputo, The Prayers and Tears of Jacques Derrida: Religion without Religion (Bloomington: Indiana University Press, 1997).

12. Jacques Derrida, Specters of Marx, trans. Peggy Kamuf (New York: Routledge, 1994), 28. 
meaning. One could regard this as a poststructuralist version of divine transcendence.

As we have seen, Taylor does demur from such a transcendent ideal insofar as it only challenges but refuses to affirm appropriate non-totalizing wholes. Still, Taylor does identify the virtual with the divine. Though Taylor officially proclaims the virtual to be neither transcendent nor immanent, the virtual does transcend all forms, does refuse capture in any form-indeed, it ever works to de-form all forms.

Furthermore, Taylor associates the destabilizing element that demarcates his understanding of the virtual with chaos, formlessness, and potentiality $(14,346$, 361). Clearly this element of chaos dominates that of structure in Taylor's metaphysical schema. Form emerges from formlessness, as chaos or the virtual selforganizes or in-forms itself - to a certain extent for a certain period of time. What I seek in a model of the divine is a balance of the poles of chaos and structure. Of course, the Western theological tradition has tended to insist that God tames chaos, indeed, with the Christian doctrine of creation from nothing, that chaos or unlimited possibility does not exist in its own right, has no ontological independence apart from God. With the coupling of predestination with creation from nothing in much Western theology, chaos was swallowed up by structure. Countervailing theologies have attempted to give chaos more of its due, including the trajectory of Nicholas of Cusa to Jacob Boehme to Friedrich Schelling and German Romantic idealism and that of process thought. In attempting to find optimal balance in a conception of God, Whitehead's process theology rejects creation from nothing (lest God be responsible for evil) but upholds the need for a principle of limitation of possibility - that chaos be effectively tamed while freedom and openness remain. ${ }^{13}$ Thus Whitehead stipulates that God's primordial nature delimits the possibilities that will apply to the universe. Catherine Keller, in the tradition of process theology, believes that Whitehead erred in taming chaos; like Taylor she maintains that chaos remains and pertains. ${ }^{14}$

I believe we can retain the notion of creation from nothing in a manner that achieves a balance between chaos and order in the divine. Among contemporary theologians, Robert C. Neville especially points the way on this issue. Unlimited potentiality, all possibility, originates in God, who primordially is utterly indeterminate. Nothing becomes determinate unless God determines it, unless God limits possibility. ${ }^{15}$ God does this in a manner that optimizes structure and freedom, determinacy and indeterminacy, in the universe. I suggest that such a model grants equal cruciality to the elements of formlessness and form in the divine. Furthermore, this model permits the locus of the real to lie in an ever-creative

13. Alfred North Whitehead, Science and the Modern World (New York: Macmillan, 1925), 178-79; Process and Reality: An Essay in Cosmology (New York: Macmillan, 1929), 522.

14. Catherine Keller, The Face of the Deep: A Theology of Becoming (New York: Routledge, 2003).

15. Robert C. Neville, "The Depths of God," Journal of the American Academy of Religion 56 (1988): $1-22$. 
self-organizing whole, namely a panentheistic divine that transcends but includes the world.

\section{Taylor's Model of Complexity and the Finite World}

What about when we move to the universe and life? I will argue that Taylor's preference for the virtual of unlimited possibility, chaos, and the abyss is even more inappropriate for human life than for the divine life. This preference does not take seriously enough our finitude and embodiment and, even more so, the difference between us and the divine, which is not just one of degree but of kind. Only God is privy to unlimited possibility. Relative to the panentheistic reference, the including whole comprehends infinite possibility in a fashion that the included parts do not. Of course, Taylor does not claim that our freedom is absolute in the sense that we can ever wholly escape our biological, social, and cultural situatedness. As we have seen, he recognizes the constraints on evolution once it has started upon a particular path. In an article in the Journal of the American Academy of Religion, Taylor highlights his purposes in writing After God. There he describes general traits of all self-organizing networks, including the following: "They display spontaneous self-organization, which occurs with parameters of constraint that leave space for the aleatory." 16 Many contemporary theological and religious thinkers, including myself, agree with Taylor in affirming some freedom, indeterminacy, and spontaneity for finite realities. What's the difference in the respective positions? We can make sense of Taylor's position as follows I believe: in order for indeterminacy to exist, the virtual/chaos/unlimited must be "present" as self-organizing wholes emerge. (I put "present" within quotation marks in that the virtual never appears as fully determinate; yet it is real, it obtains for Taylor.) This allows for creative imagination and self-organization to qualify as "arbitrary" and "out of nothing," as Taylor phrases these. Within the assumptions of Taylor's system, in the "absence" of the virtual, of chaos (if we could even have a world at all), we could not have self-organizing, non-linear wholes irreducible to the sum of their parts. We would instead have a linear world in which only an attenuated newness could happen, where even the most complicated reality would merely consist of the sum of its parts. In contrast, I see our universe as possessing laws or structures for self-organizing processes. That is, when certain conditions far from equilibrium occur, they always result in self-organizing wholes that fall within boundaries with a determinate structure. However, this structure does not mean that every detail of the whole is pre-determined; within a range that the structure allows and provides, indeterminacy pertains.

In Taylor's model of the divine as I have construed it above, I discern a tendency to reify the transcendent virtual or sublime. Even as poststructuralism had a tendency to reify différance or the unrepresentable, so I see this additional continuity between Taylor's current thought and his deconstructionist past.

16. Taylor, "Refiguring Religion," 112. 
Taylor associates dualistic religion with "either-or": things exist either in the inferior or evil realm or in the divine, perfect realm. Under "either-or," we humans can never, nor ever should, feel at home in this world: instead we long to transcend it for a home beyond. I detect some similarity of Taylor's "neither-nor" to the "either-or" pattern. Stuck in the lower realm of "either-or," a kind of "neithernor" pertains: one can identify oneself as neither fully within this world nor as fully within the world to come (until one dies). Taylor for his part lifts up a paean to "endless" or "infinite restlessness": appropriate desire "does not seek satisfaction but cultivates the dissatisfaction that issues in endless restlessness" (345; see also, $38,41,312,358)$. For Taylor, then, as for the dualist, one can never, or at least should never, feel at home in the world. One seemingly cannot wholeheartedly identify oneself with the meaningful forms of one's life in this world, because that is not the locus of the most real. Yet the elusive virtual, the most real, is too transcendent to grasp and is not any place where we can make our home. I would instead opt for a model that expresses a preference for the meaningful structures of our temporal bodies and environments, that allows us to feel at home in our bodies and in our natural, social, and cultural worlds. This does not represent an at-home-ness of stasis, which decries or resists contingency and change, but an at-home-ness in our skins that allows us to venture out in faith into an exciting and unpredictable world.

In contradistinction to Taylor as I have interpreted him, I maintain that in no sense do we and our world have experiential contact with that aspect of divinity that serves as the reservoir of all possibility, of that which is prior to embodiment. All the activity and creativity of emergent complex realities happen within structures, structures that are open, but not unlimited in any sense except that innumerable possibilities may be available within given ranges. In an obvious sense, Taylor's transcendent divine ever eludes us. On the other hand, it constitutes an "immanent transcendent" in Taylor's own words, which is in our world, in finite realities, in us. Thus, in a sense, it entails an immediacy and absolutism with respect to our connection with the divine. Clearly we do not incorporate the divine as structured particularity in Taylor's schema. Nevertheless, insofar as we imaginatively participate in the unfigurable sublimity of the virtual, we may ironically end up with a "having of the divine" more in keeping with the absolutistic modern spirit than with the postmodern spirit. Here Taylor may well be closer to monism than he realizes, by maintaining some identity of the human with the divine, à la monism. Thus, Taylor's system may ironically incorporate important features of both the dualism and the monism he wants to avoid.

\section{Taylor's Model of Complexity and our Contemporary Situation}

One commentator has characterized Taylor's take on Western history since the Reformation in this way: it has resulted in "a particular sort of globalization, a 'network culture' that is permeated in nearly all its dimensions-the social, 
the economic, the political, the religious, to name but a few-by the phenomenon of self-organizing systems that feeds off of the disruptive moment in reality.",17 Taylor indeed has rightly diagnosed the unprecedented change, in both amount and degree, involving increasing exposure to difference, of Western modernity and postmodernity. Taylor's preference for the disruptive pole might suggest optimism about our future, as might his esteeming of relationality and inter-connectivity. In the previously mentioned journal article, Taylor confesses that after many years of resistance he came "to believe that history does, in fact, have a discernible trajectory: everything is becoming increasingly interrelated."18 However, when great change and growing interrelationship occur rapidly, Taylor recognizes the negative dynamics that affect our current situation:

As connectivity increases, stability, security, and certainty decrease. Growing complexity, uncertainty, and insecurity create the desire for simplicity, certainty, and security, which leads to foundationalism on the left and the right as well as among those who admit they are believers and those who insist they are not. ${ }^{19}$

Regarding the environment and climate change, greater danger lurks: "As the networks nourishing life become more interconnected, they become less stable and secure. Though disruption and dislocation can be creative, if carried to extremes they can become destructive" (374). Indeed, we have carried them to extremes: "Processes have been set in motion that cannot be reversed, and it is unclear whether people are willing to make the changes necessary to delay, if not avoid, looming disaster." ${ }^{20}$ In passing, I will remark that Taylor blames climate change (as well as the crisis in financial markets) on actions growing out of the use of linear equilibrium models for "nonlinear, nonequilibrium processes." 21 Personally, I would put the blame more on old-fashioned sin, with people and institutions acting out of concern for short-term gain and out of convenient habits, without bothering to seek counsel from any models bearing upon the future.

In so characterizing our present cultural, political, ecological, and religious situation in dialogue with Taylor, where does hope lie? I partially share the sentiments Taylor expresses at the end of his journal article: "The acknowledgment of peril can, however, provoke committed action rather than hopeless resignation. This struggle will require faith as fragile and uncertain as the world in which we are destined to dwell." 22 Taylor's work implies that, in this situation "far from equilibrium" fraught with both special danger and opportunity, our hope lies in the formation of new systems, most crucially religious systems, of greater complexity.

17. An anonymous reviewer commenting on another manuscript.

18. Taylor, "Refiguring Religion," 117.

19. Ibid., 117-18.

20. Ibid., 118.

21. Ibid.

22. Ibid. 
But from where will these systems emerge? Tellingly, despite drawing richly from the Western theological tradition, Taylor never mentions a positive role for today's existing religions. Here I perceive a final over-emphasis on the pole of deformation and destabilization. To frame it conversely, Taylor under-emphasizes the importance of the traditions, the structures, available to our contemporary predicament. In general, I endorse Paul Connerton's stipulation that even radical or revolutionary change (in situations far from equilibrium) depends radically on the traditions it grows out of and incorporates - even when it explicitly opposes or officially replaces those traditions. ${ }^{23}$ Specifically for our time, I see no hope in attempts like Loyal Rue's to create a new religious system and mythology, informed by science but going beyond it in endorsing meaning, value, and purpose. ${ }^{24}$ Unfortunately, if such a new myth does ever take hold of humankind, I fear it will be too late to ameliorate climate change or avoid mass extinction of species. I find more hope in reform and revisioning of the major world religions, starting with my own of Christianity. This would involve a much greater emphasis on the centrality of our bodies, on nature, and on relationality than has been dominant for most of Christian history. It would I maintain include an affirmation of a basic at-home-ness in our bodies and in our natural world. Resources supporting such an emphasis have not been absent in Christian tradition, while these have increased over the past two hundred years in mainline religion and have even grown somewhat in the less rigid varieties of evangelicalism. Also given what is available from contemporary scientific, social scientific, philosophical, and theological sources, Christianity has the capability to create complex systems of meaning adaptive to our fragile context (as do the other major world religious traditions).

Therefore, let me briefly address the issue of at-home-ness in our bodies and natural world in terms of Christian structures of meaning pertaining to creation. Genesis 2:7 narrates that God formed the adam from the adamah, or in a rather literal translation of the Hebrew, that God formed the earth being from the earth. In Genesis 1:20-26 God recognizes the goodness of the animals - the embodied, sentient organisms - of sky, sea, and earth and, by implication humankind, the earth beings, whom God blesses. Psalm 139:13-14 conveys the intricacy and wonder of our bodies that God has reverently knitted. Job 39-41, through the voice in the whirlwind, strikingly expresses the bodily pleasure and integrity of diverse animals (not to mention their wildness, as God dares Job and humankind to try to tame or control them; this wildness or element of chaos, though, clearly falls within ranges that God has ordained, the God who "laid the foundation of the earth" [Job 38:4]). Neuroscientist Antonio Damasio's discussion of the "background feelings" of our body states can speak to this embodied at-home-ness in

23. Paul Connerton, How Societies Remember (New York: Cambridge, 1989), 13.

24. Loyal Rue, By the Grace of Guile: The Role of Deception in Natural History and Human Affairs (New York: Oxford, 1994). In Rue's case, that he labels such a new myth "a noble lie," which "offers up a maximum of adaptive change" as it attempts to "reenchant the earth," does not exactly inspire confidence that the effort will succeed (279). 
the world. Though normally tacit rather than attended to with full consciousness, they constitute the actual and ever-present backdrop of all we experience. From his studies of persons with certain types of brain damage, Damasio concludes that those incapable of experiencing normal body-state background feelings suffer from an impaired, fragmented sense of self. ${ }^{25}$ He goes on to theorize that such background feelings, such "primordial representations of the body," play an important role in consciousness, indeed "provide a core for the neural representation of self" and frame the very feeling of being alive. ${ }^{26}$ Damasio stipulates that emotions, which he categorizes as background, primary, or social, are never simply neutral. ${ }^{27}$ I would avow that human and animal background feelings are normally positive, providing a positive feeling of integral bodily presence, a sense of wholeness. Moreover, I regard joy, identified by Damasio as the primary emotion associated with preserving and enhancing the self, as an intensification of this normal background state. Thus, the Christian affirmation of a basic and primordial goodness to life finds a measure of support in contemporary scientific research and theorizing. ${ }^{28}$ I would add a possible interpretation of humankind's creation in the image of God. As God surveys the whole of all the smaller complex wholes deemed as good, God deems it very good (Gen 1:31). We humans, among all the creatures on earth, can conceive - though of course in a limited way-of the most complex whole that includes all constituent wholes.

Such greater reliance on structures of meaning already available in Christianity and other religious traditions allows for a faith less uncertain than Taylor's as well as a faith more likely to create structures of meaning that people will act upon with hope.

\section{Author biography}

David H. Nikkel is Associate Professor of Religion and Chair of the Department of Philosophy and Religion at the University of North Carolina, Pembroke. An elder in the East Ohio Conference of the United Methodist Church, he is pastor of the Eutaw United Church of Christ, Fayetteville, North Carolina.

25. Antonio Damasio, Descartes' Error: Emotion, Reason, and the Human Brain (New York: G.P. Putnam's Sons), 154-55.

26. Damasio, Descartes' Error, 150-51, 235ff.; see also, Antonio Damasio, The Feeling of What Happens (New York: Harcourt Brace \& Co., 1999), 37, 110, $285-87$.

27. Antonio Damasio, Looking for Spinoza: Joy, Sorrow, and the Feeling Brain (New York: Harcourt Brace \& Co., 2003), 43ff., 93.

28. Damasio, Looking for Spinoza, 13-14. 